\title{
Transcutaneous Blepharoptosis Surgery: Simultaneous Advancement of the Levator Aponeurosis and Müller's Muscle (Levator Resection)
}

\author{
Kazunami Noma ${ }^{1}$, Yasuhiro Takahashi ${ }^{2}$, Igal Leibovitch ${ }^{3}$ and Hirohiko Kakizaki ${ }^{*}, 2$ \\ ${ }^{I}$ Noma Eye Clinic, Kokutaiji, Naka-ku, Hiroshima 730-0042, Japan \\ ${ }^{2}$ Department of Ophthalmology, Aichi Medical University, Nagakute, Aichi 480-1195, Japan \\ ${ }^{3}$ Division of Oculoplastic and Orbital Surgery, Department of Ophthalmology, Tel-Aviv Medical Center, Tel-Aviv \\ University, Tel-Aviv, Israel
}

\begin{abstract}
Transcutaneous blepharoptosis surgery with simultaneous advancement of the levator aponeurosis and Müller's muscle (levator resection) is a popular surgery which is considered effective for all types of blepharoptosis except for the myogenic type. Repair of ptosis cases with good levator function yields excellent results. A good outcome can be also obtained in cases with poor levator function, however, in such cases; a large degree of levator advancement may be required, which may result in postoperative dry eyes, unnatural eyelid curvature and astigmatism. These cases are therefore better treated with sling surgery. With the right patient selection, the levator resection technique is an effective method for ptosis repair.
\end{abstract}

Keywords: Transcutaneous blepharoptosis surgery, levator aponeurosis, Müller’s muscle, levator resection.

\section{INTRODUCTION}

Blepharoptosis surgery is one of the most popular operations in the field of ophthalmic plastic and reconstructive surgery. The specific surgical method for repairing blepharoptosis is selected according to the degree of eyelid droopiness and the preoperative levator function [1]. There are 3 categories of surgical approaches to blepharoptosis surgery; transcutaneous [2], transconjunctival [3] and sling surgery [4]. The transconjunctival approach is mainly used in cases of mild to moderate ptosis with a good response to the phenylephrine test [5]. The transcutaneous approach can be applied to all types of ptosis except for the myogenic type, in which sling surgery may be best suitable [6]. Ptosis cases with levator function of $4 \mathrm{~mm}$ or more are usually repaired by levator resection [1], whereas sling surgery is used in cases of levator function under $4 \mathrm{~mm}$ [7].

There are several techniques for blepharoptosis repair which are done through a transcutaneous incision; simultaneous advancement of the levator aponeurosis and Müller's muscle (levator resection) [8], advancement of the aponeurosis only (lavatory advancement) [2] etc. The 2 transcutaneous techniques are widely performed, however, they are selected based on surgeons' preferences and not based on the pathophysiology of ptosis or factors like levator function, degree of ptosis, or type of ptosis.

Müller's muscle is believed to originate from the posterior surface of the levator palpebrae superioris (LPS) muscle [9]. More recently, modified anatomical findings regarding the origin of the levator aponeurosis and Müller's muscle have been reported [10]. It was shown that the LPS

*Address correspondence to this author at the Department of Ophthalmology, Aichi Medical University, Nagakute, Aichi 480-1195, Japan; Tel: +81-56162-3311; Fax: +81-561-63-7255; E-mail: cosme@d1.dion.ne.jp muscle is divided into 2 branches in the periphery: the superior branch which continues to the levator aponeurosis, and the inferior branch from which Müller's muscle originates. Although the thickness of each branch is almost identical, the superior branch tends to be thicker than the inferior branch.

Based on these new anatomical findings, the indications for ptosis surgery can theoretically be divided into the following categories:

1. Aponeurotic ptosis- requires aponeurosis advancement.

2. Cases of pathology in the Müller's muscle (such as Horner's syndrome) [9] - require Müller's muscle advancement. However, as Müller's muscle is structurally weak [11], simultaneous advancement of the levator aponeurosis is recommended.

3. Ptosis in hard contact lens user [12] (and in rare cases in soft contact lens user [13]) - as the pathology is not purely in the aponeurosis but rather in both the aponeurosis and Müller's muscle [14], levator resection is recommended.

4. In cases of severe ptosis - levator resection or sling surgery should be performed. Although each procedure is effective irrespective of the associated pathology, comparative long term results have not been reported so far.

In this review, we present the levator resection technique and discuss the advantage and disadvantage.

\section{THE SURGICAL TECHNIQUE}

After marking a horizontal line along the upper skin crease extending to the lateral canthal commissure and about 6 to $7 \mathrm{~mm}$ from the upper eyelid margin, a local anesthetic 
solution ( $2 \mathrm{ml}$ of $1 \%$ lidocaine with $1 / 100,000$ epinephrine) is administered.

The skin is then incised with a number 15 blade. The subcutaneous tissue and the orbicularis oculi muscle are dissected with scissors, and the levator aponeurosis can then be visualized.

The levator aponeurosis is detached from the tarsal plate (Fig. 1), and the levator complex, including Müller's muscle and the levator aponeurosis, are continuously detached from the conjunctiva (Fig. 2). Involutional change of the Müller's muscle (thin appearance and/or fat infiltration, etc.) may be seen in some cases [15]. A negative phenylephrine test can be seen in patients with marked fatty infiltration [16].

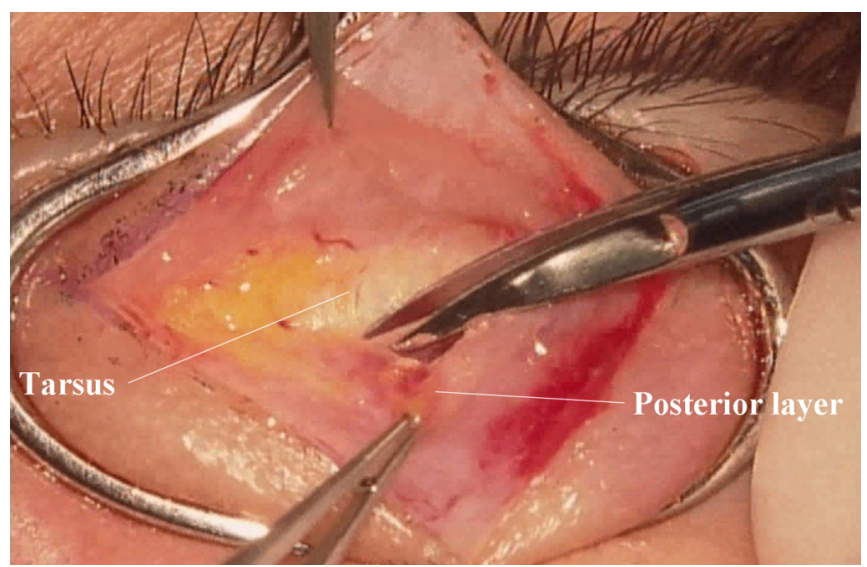

Fig. (1). (Upside down view: surgeon's view) Detachment of the posterior layer of the levator aponeurosis from the tarsal plate.

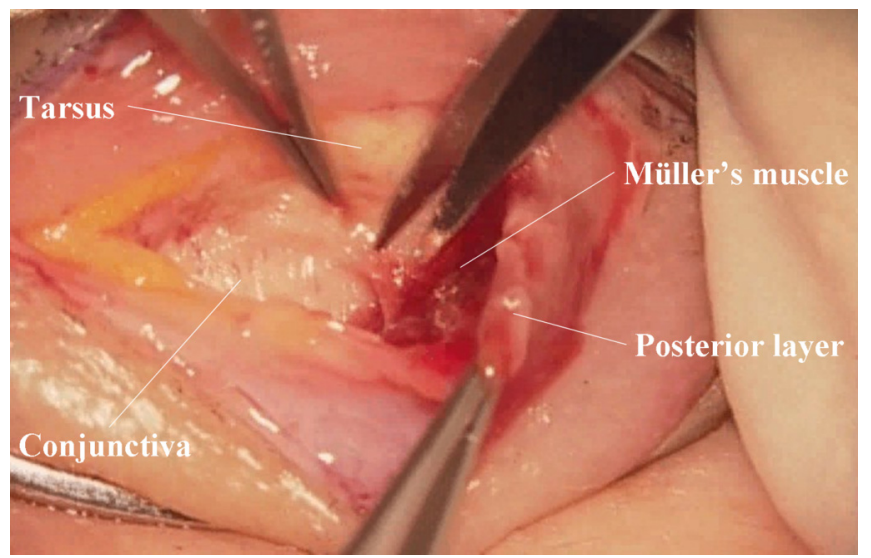

Fig. (2). (Surgeon's view) Detachment of Müller's muscle from the conjunctiva.

The anterior aspect of the levator aponeurosis is also detached from the orbicularis oculi muscle, and the white line [17-19], which is the confluent part between the levator aponeurosis and the orbital septum, is confirmed (Fig. 3). Of notice here is the 3-dimentional structure of the merging point between the levator aponeurosis and the orbital septum. When the orbital septum above the white line is incised transversely, the white glistening anterior layer of the levator aponeurosis can be seen (Fig. 4). Old patients with fair to poor levator function may have a misleading fatty degeneration in the aponeurosis [15].

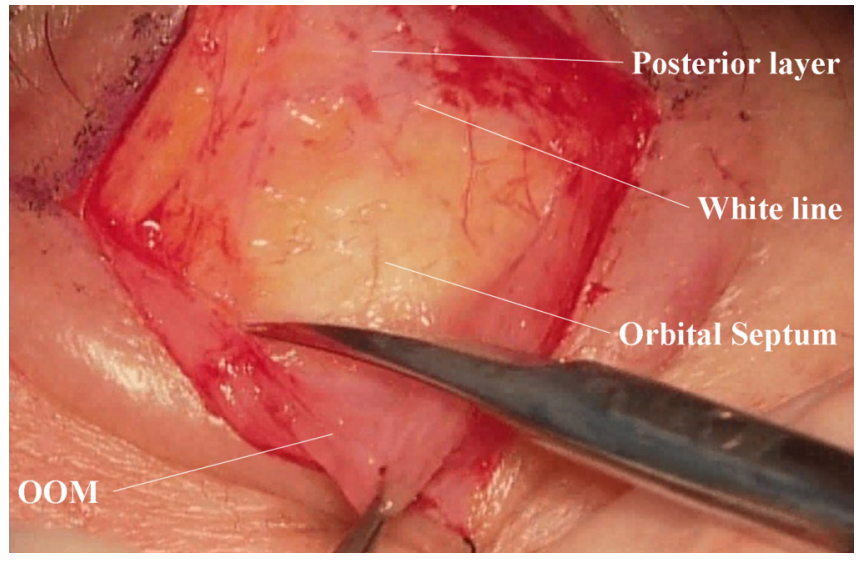

Fig. (3). (Surgeon's view) Detachment of the orbicularis oculi muscle from the posterior layer of the levator aponeurosis and the orbital septum. The white line is visualized. The orbital fat, which is seen through the translucent orbital septum, descents to the white line. OOM: orbicularis oculi muscle.

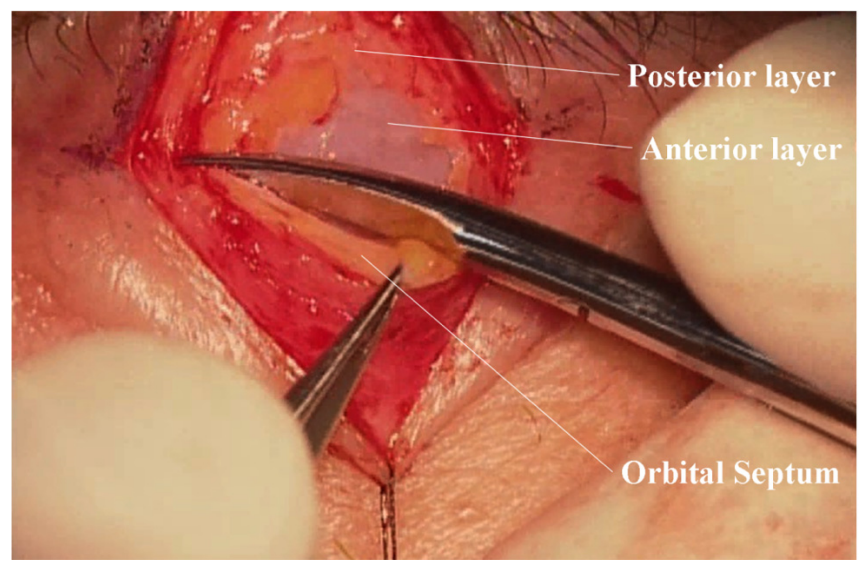

Fig. (4). (Surgeon's view) Transverse incision of the orbital septum. The anterior layer of the levator aponeurosis is visualized.

The centre of the eyelid fissure is then determined [17]. First, the eyelid margin above the centre of the pupil is pulled superiorly and an isoscele triangle is created, the part of which corresponds to the centre of the eyelid fissure. Then, the centre of the levator aponeurosis is determined by making an isosceles triangle of the levator aponeurosis with inferior traction, the tip of which corresponds to the centre of the levator aponeurosis [18]. These steps are essential to avoid a postoperative temporal flare [19].

A 6-0 nylon or vicryl ${ }^{\circledR}$ suture is passed from the centre of the levator aponeurosis, just a few millimeters above the white line, and fixated to central part of the tarsal plate, by taking a partial thickness bite at around the middle height of the tarsus. The suture is tightly knotted four times to prevent loosening.

As the medial horn of the levator aponeurosis is structurally weaker than the lateral horn [19], therefore the medial part should be advanced about $2 \mathrm{~mm}$ more than the central part. In addition, as the levator aponeurosis is narrow proximally and wider distally, the narrow part of the aponeurosis should be sutured in cases that require a significant advancement. The medial horn supporting 
ligament can be used as a marking point to the medial margin of the levator aponeurosis [20].

At this stage, intraoperative quantification is performed while the patient is in a sitting position [21]. If overcorrection is noted (Fig. 5A), the levator complex is resutured more distally (Fig. 5B). This procedure is continued untill the desired height and contour of the upper eyelid are achieved (Fig. 5C). Two additional 6-0 nylon or vicryl ${ }^{\circledR}$ sutures are added medialy and laterally to form a more naturally-looking upper eyelid curvature. When there is no lagophthalmos, the redundant aponeurosis can be resected. When lagophthalmos exists, a forced eyelid closure test (downward eyelid push with a finger) is performed [22], and if the residual lagophthalmols is less than $2 \mathrm{~mm}$, the chance of postoperative lagophtahlmos is very low. Any redundant eyelid skin, can now be also removed.

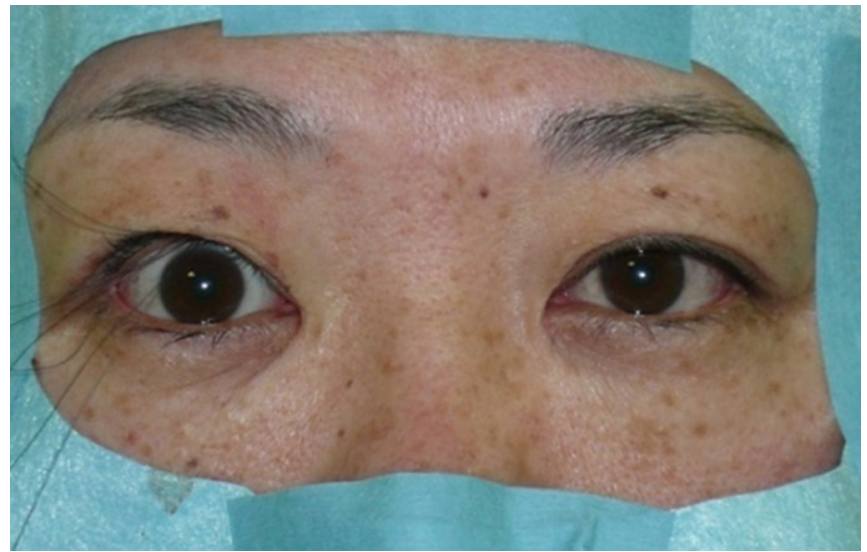

Fig. (5A). Intraoperative quantification in the sitting position. Overcorrection is shown in the right side.

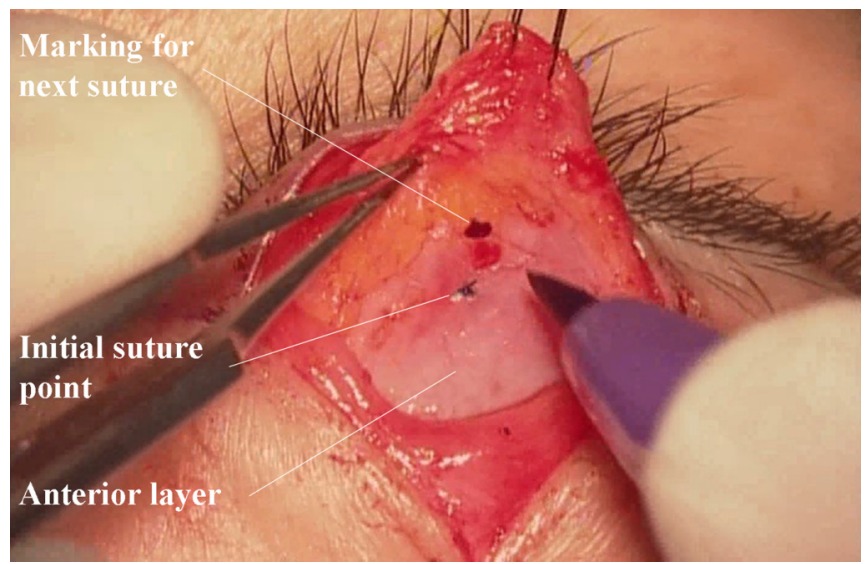

Fig. (5B). (Surgeon's view) Re-fixation of the levator complex. The levator complex is re-sutured at a more distal point.

The double eyelid is formed by 3 separate sutures, taking care not to cause inappropriate outward rolling of the eyelid margin (Fig. 6). This step is known as the "Asian blepharoplasty technique" [23]. In Caucasians and higher eyelid crease patients, this step is not required, and when the skin is closed with 6-0 nylon or vicryl ${ }^{\mathbb{P}}$ sutures they are also passed through the aponeurosis. The intraoperative quantification in the sitting position is shown to match the final posoperative outcome after 6 weeks (Fig. 7) [21].

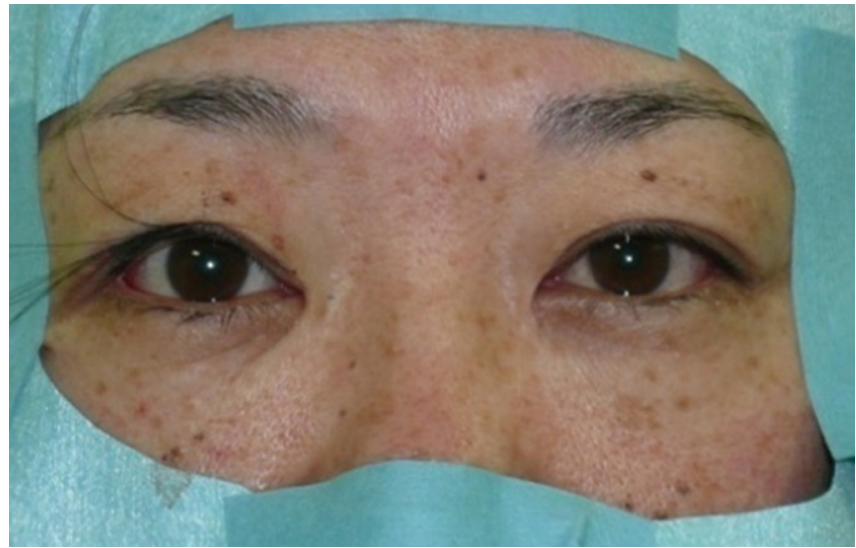

Fig. (5C). Re-examination of the upper eyelid height and curvature in the sitting position.

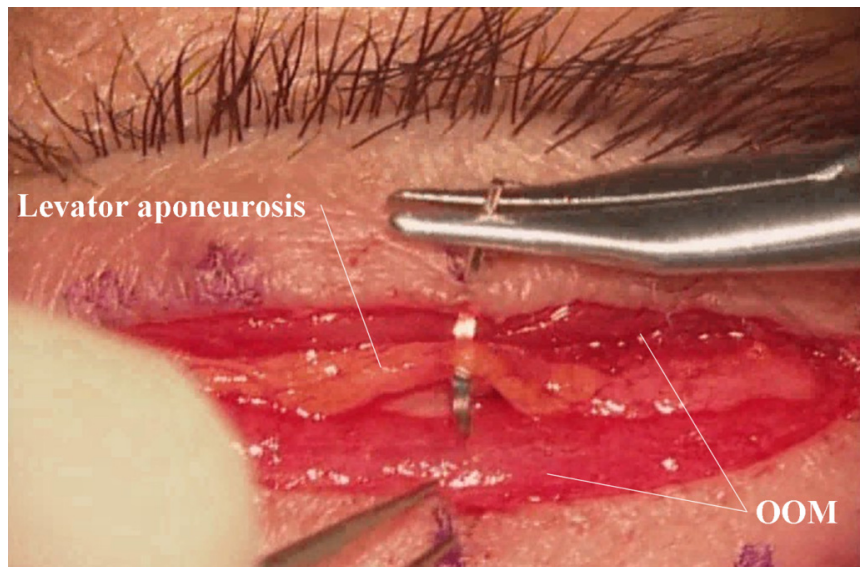

Fig. (6). (Surgeon's view) Creation of the upper eyelid crease. OOM: orbicularis oculi muscle.

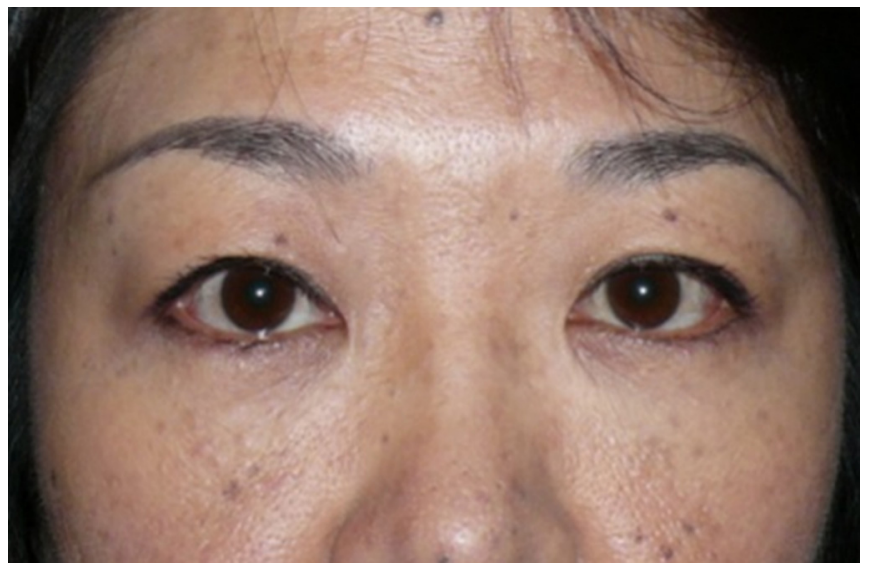

Fig. (7). Postoperative outcome at 6 weeks post-operatively. The patient is in a sitting position.

\section{DISCUSSIONS}

Patients with aponeurotic ptosis frequently show involutional or post-inflammatory changes in Müller's muscle in addition to the aponeurotic changes $[14,15,24]$. Transcutaneous ptosis surgery with advancement of both the levator aponeurosis and Müller's muscle (levator resection) is anatomically and pathophysiologically more appropriate than the other techniques for ptosis surgery, and results in a more naturally-looking upper eyelid contour. 
The levator resection advances the levator aponeurosis as well as Müller's muscle. Cases with levator function of 10 $\mathrm{mm}$ or more usually require a small degree of advancement of the levator complex [25]. In addition, cases with a poor response to the phenylephrine test, which mostly result from involutional changes in Müller's muscle [16], may require a smaller degree of advancement of the levator tissue if levator resection is chosen over the other types of ptosis repair techniques. This is because the levator resection advances both layers of the levator complex.

Cases with poor levator function may require a very significant advancement of the levator complex, which may cause dry eyes [26] because of a poorer fitting between the lower part of the upper eyelid and the underlying cornea. In addition, as the levator aponeurosis is narrower in its proximal part [19], a larger degree of advancement may cause difficulties in appropriate fixation of the levator aponeurosis to the tarsal plate, and result in an unnatural upper eyelid curvature. Furthermore, postoperative astigmatism may occur in such cases of advancement [27], which may be of significant importance in children undergoing this surgery, and who may develop amblyopia. Levator resection was shown to cause more postoperative astigmatism than the sling operation [28]. A possible reason is that the advanced aponeurosis presses the globe and changes the corneal shape [27]. A patient with ptosis who intends to undergo cataract or refractive surgery in the future should consider having his or her ptosis surgery done first to avoid any additional refractive changes [27].

Some surgeons believe that Müller's muscle should not be manipulated during ptosis surgery because it acts as a muscle spindle to the LPS muscle [29]. However, with a positive phenylephrine test, the levator complex is not advanced much in the levator resection, and a certain amount of Müller's muscle is spared, and its function is partially preserved. That theory has several drawbacks. First, cases with no response to the phenylephrine test will not react to the sympathetic stimulation. Second, in cases where only the levator aponeurosis is advanced, Müller's muscle is loosened and cannot react to the sympathetic stimulation, possibly resulting in denervation atrophy. Third, the sympathetic reflex from Müller's muscle cannot be explained only by the Müller's muscle itself, and the smooth muscle fibers in the orbit should also be taken into consideration [30]. Forth, studies on fetuses have shown that the LPS muscle has its own muscle spindles, although their number is smaller than that of the other extraocular muscles [31].

In conclusion, the levator resection is a commonly used procedure that addresses the pathophysiology of most types of ptosis except for the myogenic type. Cases with good levator function, irrespective of the response in the phenylephrine test, are best suitable for this technique. In cases with poor levator function where a large degree of levator complex advancement is required, it may result in undesired ocular side effects. We believe that with the right patient selection, the levator resection technique is an effective method for ptosis repair.

\section{CONFLICT OF INTEREST}

The authors have no financial support and no financial interest related to this manuscript.

\section{ABBREVIATIONS}

\section{LPS $=$ Levator palpebrae superioris}

\section{REFERENCES}

[1] Finsterer J. Ptosis: causes, presentation, and management. Aesth Plast Surg 2003; 27: 193-204.

[2] Anderson RL, Dixon RS. Aponeurotic ptosis surgery. Arch Ophthalmol 1979; 97: 1123-8.

[3] Putterman AM, Urist MJ. Müller's muscle-conjunctival resection ptosis procedure. Ophthalmic Surg 1978; 9: 27-32.

[4] Crawford JS. Repair of ptosis using frontalis muscles and fascia lata: a 20-year review. Ophthalmic Surg 1977; 8: 31-40.

[5] Ben Simon GJ, Lee S, Schwarcz RM, McCann JD, Goldberg RA. External levator advancement vs Müller's muscle-conjunctival resection for correction of upper eyelid involutional ptosis. Am J Ophthalmol 2005; 140: 426-32.

[6] Wong VA, Beckingsale PS, Oley CA, Sullivan TJ. Management of myogenic ptosis. Ophthalmology 2002; 109: 1023-31.

[7] Dresner S. Ptosis management: a practical approach. In: Chen WP, Ed. Oculoplastic Surgery: The Essentials. New York: Thieme 2001; pp. 75-88.

[8] Older JJ. Upper lid blepharoplasty and ptosis repair using a transcutaneous approach. Ophthal Plast Reconstr Surg 1994; 10: 146-9.

[9] Beard C. Müller's superior tarsal muscle: anatomy, physiology, and clinical significance. Ann Plast Surg 1985; 14: 324-33.

[10] Kakizaki H, Prabhakaran V, Pradeep T, Malhotra R, Selva D. Peripheral branching of levator superioris muscle and Müller muscle origin. Am J Ophthalmol 2009; 148: 800-3.

[11] Kuwabara T, Cogan DG, Johnson CC. Structure of the muscles of the upper eyelid. Arch Ophthalmol 93; 1975: 1189-97.

[12] van den Bosch WA, Lemij HG. Blepharoptosis induced by prolonged hard contact lens wear. Ophthalmology 1992; 99: 175965.

[13] Reddy AK, Foroozan R, Arat YO, Edmond JC, Yen MT. Ptosis in young soft contact lens wearers. Ophthalmology 2007; 114: 2370.

[14] Watanabe A, Araki B, Noso K, Kakizaki H, Kinoshita S. Histopathology of blepharoptosis induced by prolonged hard contact lens wear. Am J Ophthalmol 2006; 141: 1092-6.

[15] Cahill KV, Buerger Jr GF, Johnson BL. Ptosis associated with fatty infiltration of Müller's muscle and levator muscle. Ophthal Plast Reconstr Surg 1986; 2: 213-7.

[16] Baldwin HC, Bhagey J, Khooshabeh R. Open sky Müller muscleconjunctival resection in phenylephrine test-negative blepharoptosis patients. Ophthal Plast Reconstr Surg 2001; 21 276-80.

[17] Kakizaki H, Zako M, Mito H, Katori N, Iwaki M. A guide to making a natural eyelid margin curvature in blepharoptosis surgery. Acta Ophthalmol Scand 2004; 82: 240-1.

[18] Kakizaki H, Zako M, Iwaki M. A guide determining center of levator aponeurosis and palpebral fissure width in blepharoptosis surgery. Eur J Plast Surg 2007; 29: 309-11.

[19] Kakizaki H, Zako M, Ide A, et al. Causes of undercorrection of medial palpebral fissures in blepharoptosis surgery. Ophthal Plast Reconstr Surg 2004; 20: 198-201.

[20] Kakizaki H, Zako M, Nakano T, et al. Medial horn supporting ligament in Asian upper eyelids. Orbit 2008; 27: 91-96.

[21] Takahashi Y, Kakizaki H, Mito H, Shiraki K. Assessment of the predictive value of intraoperative eyelid height: measurements in sitting and supine positions during blepharoptosis repair. Ophthal Plast Reconstr Surg 2007; 23: 119-21.

[22] Kakizaki $\mathrm{H}$, Zako $\mathrm{M}$, Mito $\mathrm{H}$, Iwaki $\mathrm{M}$. Intraoperative quantification using finger force for involutional blepharoptosis without postoperative lagophthalmos. Jpn J Ophthalmol 2006; 50: $135-40$.

[23] McCurdy JA Jr. Asian blepharoplasty. In: McCurdy JA Jr, Lam SM, Eds. Cosmetic Surgery of the Asian Face. $2^{\text {nd }}$ ed, New York: Thieme 2005; pp. 8-41.

[24] Berke RN, Hackensack NJ, Wadsworth JAC. Histology of levator muscle in congenital and acquired ptosis. Arch Ophthalmol 1955; 53: 413-28.

[25] Cates CA, Tyers AG. Outcomes of anterior levator resection in congenital blepharoptosis. Eye 2001; 15: 770-3.

[26] Kakizaki H. Levator resection. In: Gankeiseigoko Tora No Maki. Tokyo: Medical Aoi 2009; pp. 9-24. 
[27] Zinkernagel MS, Ebneter A, Ammann-Rauch D. Effect of upper eyelid surgery on corneal topography. Arch Ophthalmol 2007; 125: $1610-2$.

[28] Cadera W, Orton RB, Hakim O. Changes in astigmatism after surgery for congenital ptosis. J Pediatr Ophthalmol Strabismus 1992; 29: 85-8.

[29] Matsuo K. Stretching of the Mueller muscle results in involuntary contraction of the levator muscle. Ophthal Plast Reconstr Surg 2002; 18: 5-10.
[30] Miller JM, Demer JL, Poukens V, Pavlovski DS, Nguyen HN, Rossi EA. Extraocular connective tissue architecture. J Vis 2003; 3 : 240-51.

[31] Korzeniowska-Kromer E, Wójtowicz-Kaczmarek K. Muscle spindles in the levator palpebrae superioris muscle of human foetuses. Folia Morphol (Warsz) 2003; 62: 289-90.

Received: April 15, 2010

(C) Noma et al.; Licensee Bentham Open.

This is an open access article licensed under the terms of the Creative Commons Attribution Non-Commercial License (http: //creativecommons.org/licenses/by$\mathrm{nc} / 3.0 /$ ) which permits unrestricted, non-commercial use, distribution and reproduction in any medium, provided the work is properly cited. 